\title{
EFFECTS OF 21-AMINOSTEROID U-74389G ON AMIODARONE-INDUCED PULMONARY TOXICITY IN RATS
}

\author{
Galya Ts. STAVREVA ${ }^{1 凶}$, Violeta Y. DANCHEVA ${ }^{2}$, Lyudmil G. TERZIEV ${ }^{3}$, Plamen K. KRASTEV ${ }^{1}$ \\ ${ }^{1}$ Department of Pharmacology and Toxicology, Medical University - Pleven, Bulgaria \\ ${ }^{2}$ Sector of Disaster Medicine, Medical University, Pleven, Bulgaria \\ ${ }^{3}$ Sector of Clinical Immunology and Allergology, Medical University - Pleven, Bulgaria
}

Received 21 June 2019, Accepted 03 August 2019

https://doi.org/10.31688/ABMU.2019.54.3.01

\begin{abstract}
Introduction. The widely used antiarrhythmic amiodarone (AD) has been linked to many health problems, including pulmonary toxicity.

The objective of the study. In the present study we assessed the protective effect of 21-aminosteroid U-74389 G due to its antioxidative and membrane-stabilizing potency on amiodarone-induced pneumotoxicity in rats.

Material and methods. The study was carried out on 72 male Wistar rats, divided into four groups: (1) - control; (2) - treated with AD intratracheally; (3) - treated with AD and U-74389G; (4) - treated with U-74389G alone. AD was instilled twice on days 0 and $2(6.25$ $\mathrm{mg} / \mathrm{kg}$ with a concentration $3.125 \mathrm{mg} / \mathrm{mL}$ ). U-74389G was injected intraperitoneally on days 0,1 and 2 in a dose of $5 \mathrm{mg} / \mathrm{kg}$. The activity of super-oxide dismutase (SOD), catalase (CAT), glutathione peroxidase (GP), malondialdehyde (MDA) content and hydroxyproline content were performed on days 3, 7, 14 and 28 in lung homogenate. Hydroperoxide concentrations were measured in the plasma.
\end{abstract}

Results. AD administration affected antioxidant defense system in the lungs, promoted lipid peroxidation, and caused pulmonary fibrosis.

\section{Résumé}

Les effects de 21-aminosteroide U-74389G sur la toxicite pulmonaire induite par l'amiodarone chez les rats

Introduction. L'amiodarone antiarythmique (AD), largement utilisée, a été associée à de nombreux problèmes de santé, notamment la toxicité pulmonaire.

L'objectif de l'étude. Dans la présente étude, nous avons évalué l'effet protecteur de 21-aminostéroide $\mathrm{U}-74389 \mathrm{G}$ en raison de son pouvoir antioxydant et stabilisateur de la membrane sur la pneumotoxicité induite sur les rats.

Matériel et méthodes. L'expérience a été réalisée sur 72 rats Wistar mâles, répartis en quatre groupes: (1) contrôle; (2) - traités avec AD par voie intratrachéale; (3) - traités avec AD et U-74389G; (4) - traités avec seul U-74389G. AD a été instillée deux fois aux jours 0 et $2(6,25 \mathrm{mg} / \mathrm{kg}$, dans une concentration de 3.125 $\mathrm{mg} / \mathrm{mL})$. U-74389G a été injecté intrapéritonéalement aux jours 0,1 et 2 à une dose de $5 \mathrm{mg} / \mathrm{kg}$. L'activité de la superoxyde-dismutase (SOD), de la catalase (CAT), de la glutathion peroxydase (GP), du malondialdéhyde (MDA) et de l'hydroxyproline a été réalisée aux jours 3, 7, 14 et 28 dans l'homogénat du poumon. Les $\triangle$ Address for correspondence:
Galya STAVREVA

Department of Pharmacology and Toxicology, Medical University of Pleven, Bulgaria

Address: 1, St. Kliment Ohridski str., Pleven, 5800, Bulgaria

E-mail: drstavreva@yahoo.com; Phone: 0035964884131 
Conclusions. The 21-aminosteroid U-74389G significantly inhibited lipid peroxidation and mitigated fibrous changes in rat lungs provoked by AD.

Keywords: amiodarone, U-74389G, antioxidant system, lipid peroxidation.

\section{Abbreviations:}

$\mathrm{AD}$ - amiodarone

CAT - catalase

GP - glutathione peroxidase

$\mathrm{ROOH}$ - hydroperoxide

LH - lung homogenate

MDA - malondialdehyde

SOD - super-oxide dismutase

\section{INTRODUCTION}

The lungs are a common target of various toxic agents. Currently, more than 380 drugs could cause toxic lung injury ${ }^{1}$. The widely used iodine-containing antiarrhythmic amiodarone (AD) causes serious pulmonary toxicity ${ }^{2-4}$. It accumulates selectively in adipose tissue and in several organs such as lungs, liver, spleen, cornea ${ }^{5,6}$. Amiodarone has a long elimination half-life 30 to 108 days, with a volume of distribution of about $5000 \mathrm{~L}^{3}$. Although the therapeutic use is directed to the cardiovascular system, the concentration of $\mathrm{AD}$ measured in the lungs exceeds that in the heart ${ }^{2}$. On the other hand, its principal metabolite $\mathrm{N}$-desethylamiodarone can accumulate in the lungs in concentration four times higher than $\mathrm{AD}$ concentration $^{5,7}$.

The frequency of amiodarone-induced pulmonary toxicity is between $5-15 \%$, with a mortality rate from 10 to $23 \%{ }^{8}$. The incidence of this adverse drug reaction has decreased with the treatment with lower doses of $\mathrm{AD}$, although it can be observed at any dose.

Although AD's pulmonary toxicity may be due to high lung concentration of $\mathrm{AD}$ and its derivatives, several mechanisms have been discussed to clarify this complication ${ }^{9,10}$.

The most relevant hypotheses are direct cytotoxic effects on type II pneumocytes and lung parenchyma; indirectly, by means of an immunologically-mediated response in genetically predisposed individuals, and direct drug-induced phospholipidosis of alveolar macrophages and type II pneumocytes ${ }^{9-11}$.

Several studies have demonstrated an impairment of mitochondrial structure and function produced by amiodarone ${ }^{11}$. It is estimated that $\mathrm{AD}$ has affinity to these organelles and this makes them likely target for AD-induced damages. concentrations d'hydroperoxyde ont été mesurées dans le plasma.

Résultats. L'administration de la $\mathrm{AD}$ a affecté le système de défense antioxydant dans les poumons, a favorisé la peroxydation des lipides et a provoqué une fibrose pulmonaire.

Conclusions. Le 21-aminostéroide U-74389G a inhibé de manière significative la peroxydation lipidique et a atténué les changements fibreux dans les poumons du rat provoquées par l'amiodarone.

Mots-clés: amiodarone, U-74389G, système de défense antioxydant, peroxydation lipidique.

\section{THE OBJECTIVE OF THE STUDY}

Since glucocorticoids are frequently applied for the therapy of AD-induced pulmonary toxicity, we aimed to examine the effect of synthetic 21 -aminosteroid, U74389G, analogue of methylprednisolone $e^{12,13}$, on the antioxidant defense system, lipid peroxidation and lung fibrosis development.

\section{Material and Methods}

Amiodarone hydrochloride (), U-74389G (CAS $\mathrm{N}^{\circ}$ 153190-29-5) and all chemicals and reagents were purchased from Sigma-Aldrich Company.

\section{Animals and Experimental Protocol}

The experiment was approved by the Medical University - Pleven (Bulgaria) Ethics Committee and was conducted in accordance with the Animal Welfare Regulations.

The study was carried out on 72 male Wistar rats (weight 220-250 g, age 4 months). The animals were purchased from the Research and Laboratory Animal Breeding Center of Slivnitsa (Bulgaria). The animals were kept at the University vivarium for 1 month, under optimal laboratory condition (temperature of $22 \pm 2^{\circ} \mathrm{C}$ and humidity of $50 \pm 10 \%$ ), by providing normal pellet diet and water ad libitum.

The rats were divided into four groups: group 1 , controls, treated with sterile distilled water intratracheally twice on days 0 and 2; group 2, treated with amiodarone, instilled intratracheally twice on days 0 and $2(6.25 \mathrm{mg} / \mathrm{kg}$, as an aqueous solution with a concentration $\left.3.125 \mathrm{mg} / \mathrm{mL}^{14}\right)$; group 3, treated with amiodarone intratracheally on days 0 and 2 and with U-74389 G intraperitoneally on days 0,1 , and 2 in a dose of $5 \mathrm{mg} / \mathrm{kg}$; group 4, injected with U-74389G at the same dose and time as the previous group. 
Table 1. Superoxide dismutase (SOD), catalase (CAT), and glutathione peroxidase (GP) activity in lung homogenate on day 3 and 7 after intratracheal AD instillation

\begin{tabular}{|c|c|c|c|c|c|c|}
\hline \multirow[b]{3}{*}{ Groups } & \multicolumn{2}{|c|}{ SOD activity } & \multicolumn{2}{|c|}{ CAT activity } & \multicolumn{2}{|c|}{ GP activity } \\
\hline & Day 3 & Day 7 & Day 3 & Day 7 & Day 3 & Day 7 \\
\hline & $\begin{array}{c}U / g \\
\text { mean } \pm S E M\end{array}$ & $\begin{array}{c}U / g \\
\text { mean } \pm \text { SEM }\end{array}$ & $\begin{array}{c}m c a t / g \\
m e a n \pm S E M\end{array}$ & $\begin{array}{c}\text { mcat } / g \\
\text { mean } \pm \text { SEM }\end{array}$ & $\begin{array}{c}U / g \\
m e a n \pm S E M\end{array}$ & $\begin{array}{c}U / g \\
\text { mean } \pm \text { SEM }\end{array}$ \\
\hline $\begin{array}{l}\text { Group } 1 \\
\text { (contr.) }\end{array}$ & $325.42 \pm 54.18$ & $325.42 \pm 54.18$ & $9.51 \pm 0.47$ & $9.50 \pm 0.47$ & $60.12 \pm 5.03$ & $62.16 \pm 7.30$ \\
\hline $\begin{array}{l}\text { Group } 2 \\
\text { (AD) }\end{array}$ & $217.60 \pm 51.39^{*}$ & $272.81 \pm 26.79$ & $11.67 \pm 0.22^{*}$ & $10.96 \pm 0.46$ & $43.21 \pm 2.78$ & $38.84 \pm 2.03 *$ \\
\hline $\begin{array}{c}\text { Group } 3 \\
(\mathrm{AD}+\mathrm{U} 74389 \mathrm{G})\end{array}$ & $242.43 \pm 55.76^{*}$ & $284.57 \pm 45.68$ & $10.89 \pm 0.47^{*}$ & $9.30 \pm 0.82$ & $44.86 \pm 4.75$ & $40.08 \pm 3.09^{*}$ \\
\hline $\begin{array}{c}\text { Group } 4 \\
\text { (U74389G) }\end{array}$ & $303.42 \pm 50.86$ & $297.87 \pm 44.63$ & $10.19 \pm 0.22$ & $9.84 \pm 0.33$ & $56.39 \pm 5.33$ & $50.92 \pm 4.03$ \\
\hline
\end{tabular}

Abbreviations: AD - amiodarone, CAT - catalase, GP - glutathione peroxidase, SOD - superoxide dismutase. ${ }^{*} \mathrm{P}<0.05$ vs. control group

Amiodarone was dissolved in distilled water at a temperature of $60^{\circ} \mathrm{C}$ and cooled to room temperature. U-74389G was dissolved in CS-4 solution (water solution of $20 \mathrm{mM}$ citric acid monohydrate, $3.2 \mathrm{mM}$ sodium citrate dehydrate, $77 \mathrm{mM} \mathrm{NaCl}, \mathrm{pH}=3$ ) in a concentration of $2 \mathrm{mg} / \mathrm{mL}$.

\section{Biochemical assays of lung homogenate}

Under thiopental anesthesia $(50 \mathrm{mg} / \mathrm{kg})$, the animals were sacrificed by exsanguination on days $3,7,14$, and 28. The lungs were perfused with 30 $\mathrm{mL}$ saline in situ via the right heart ventricle, after opening the chest. The right lung was removed and was homogenized with ice-cold $0.25 \mathrm{M}$ sucrose in Tris-HCl, pH 7.4 (in a ratio of 1:10). The homogenate was centrifuged at $9000 \mathrm{~g}(30 \mathrm{~min})$ and the supernatant was stored on ice. For the measurement of malondialdehyde (MDA) content, lung tissue homogenized with $\mathrm{KCl}$ in a ratio of 1:10 was used. Super-oxide dismutase (SOD) activity was measured by the method of Maral et al ${ }^{15}$; catalase (CAT) activity was measured by the method of Koroljuk et $\mathrm{a}^{16}$; glutathione peroxidase (GP) activity was measured by the method of Bergmeyer et $\mathrm{al}^{17}$, and MDA content was measured by the method of Ohkawa et $\mathrm{al}^{18}$. The content of hydroxyproline in $\mu \mathrm{g} / \mathrm{mL}$ was measured by the method of Bergman and Loxley ${ }^{19}$. The plasma hydroperoxide concentrations in $\mathrm{nmol} / \mathrm{mL}(\mathrm{ROOH})$ were measured by the method of Yagy $y^{20}$.

\section{Statistical analysis}

The results were presented as mean values \pm S.E.M. and were tested by one-way ANOVA, followed by Fisher's least significant difference procedure as a post-hoc test. A level of $P<0.05$ was considered significant. Analyses were performed using STATGRAPHICS ${ }^{\circledR}$ Centurion XV statistical software.

\section{Results}

The activity of superoxide dismutase decreased significantly on day $3(67 \%)$ in group 2 compared to the controls. SOD activity did not change significantly with combined treatment (group 3) compared with group 2 (AD group). Catalase activity increased significantly on day 3 in groups 2 and 3 as compared with control animals. CAT activity on day 3 increased less in group $3(114 \%)$ than in group 2 (123\%). Glutathione peroxidase activity diminished significantly in both experimental groups ( 2 and 3 ) on days 3 and 7 , as compared with the controls. The decrease in enzyme activity in group 3 (AD and U-74389G) was non-significantly less than that in group 2 at the same time points. The activities of antioxidant enzymes in lung homogenate are presented in Table 1.

The hydroperoxide concentrations (Fig. 1) were significantly increased in the plasma of AD-treated rats (group 2) on day 7, when it reached $146 \%$ compared to the controls. The combination of $\mathrm{AD}$ and U-74389G (group 3) also elevated this marker, but it remained significantly lower as compared to group 2 at the same time point. Measurement of MDA content (Fig. 2) in lung homogenate showed a similar pattern of change. The content of MDA was increased in the group, treated solely with AD on day 7 (169\%) as compared to the controls. The combined treatment with $A D$ and lazaroid decreased significantly this index at the same day as compared to group 2 .

Isolated application of AD (group 2) significantly increased the hydroxyproline content (Figure 3) on days 14 and 28 to $249 \%$ and $235 \%$, respectively. The lazaroid U-74389G in combination with AD (group 3) significantly decreased this marker at the same time points as compared to group 2 (AD alone). 


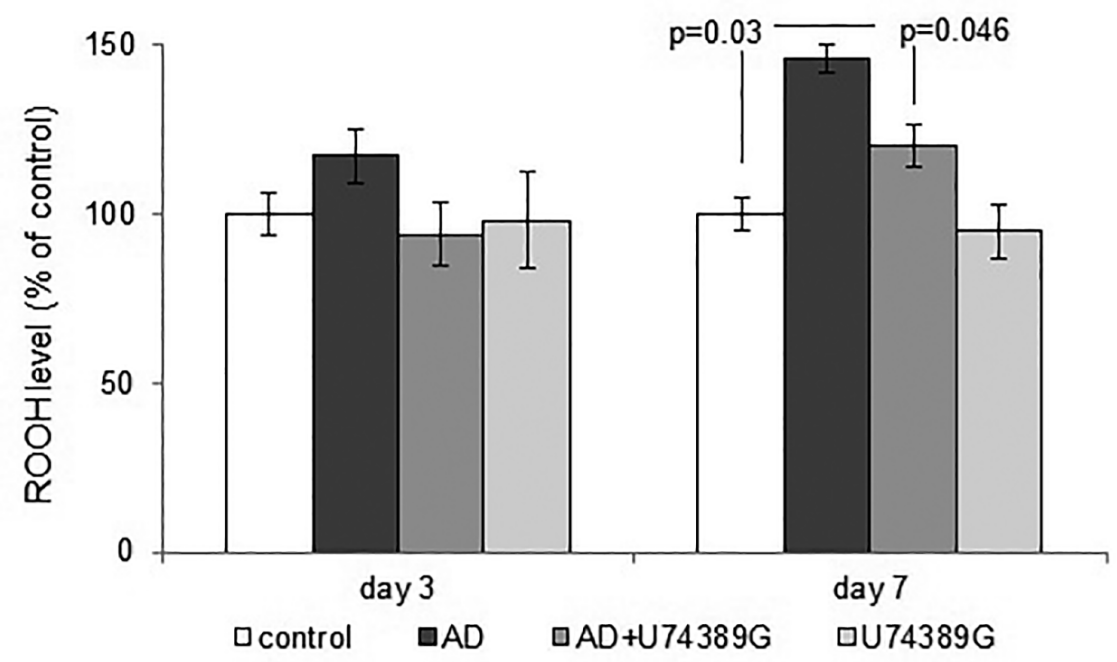

Figure 1. Hydroperoxide concentrations in plasma on days 3 and 7 after intratracheal AD instillation. AD - amiodarone, $\mathrm{ROOH}$ - hydroperoxide.

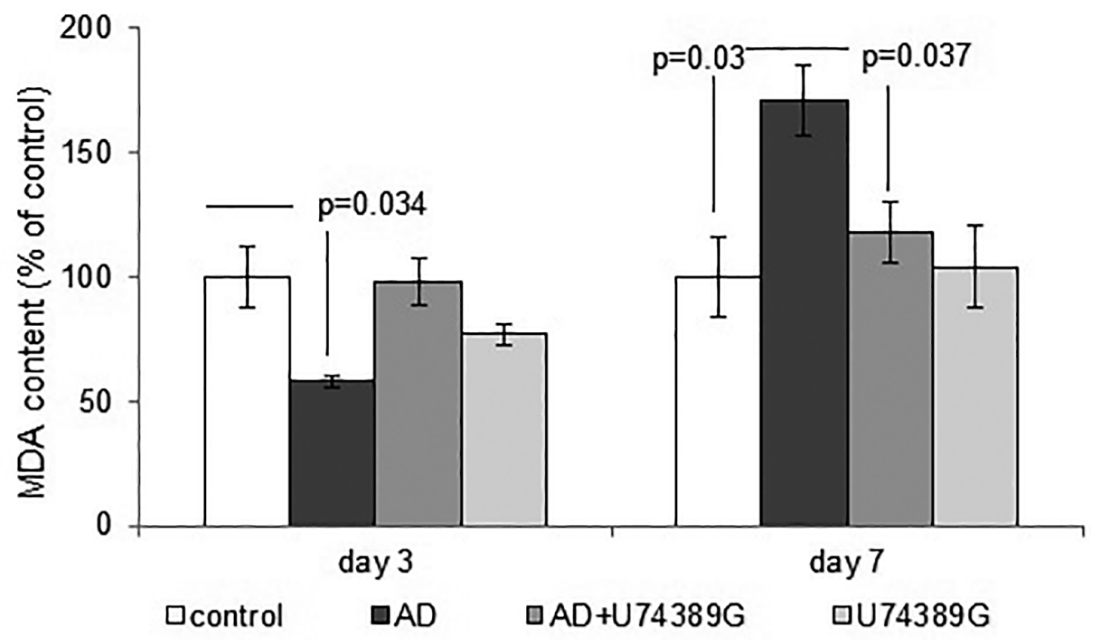

Figure 2. Malondialdehyde content in lung homogenate on days 3 and 7 after intratracheal AD instillation. AD - amiodarone, MDA - malondialdehyde.

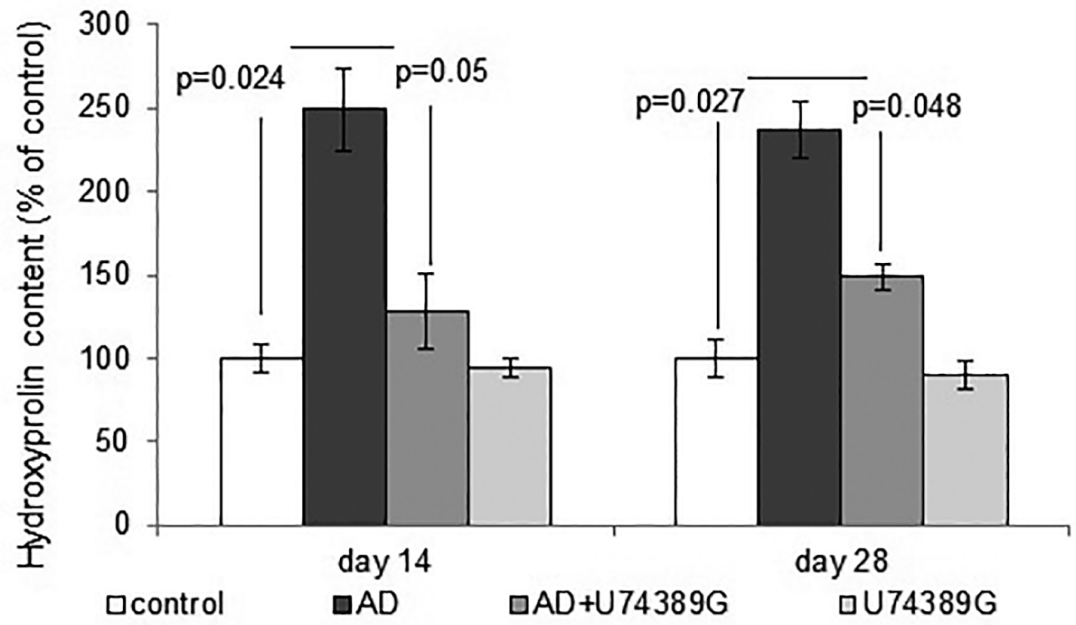

Figure 3. Hydroxyproline content in lung homogenate on days 14 and 28 after intratracheal $\mathrm{AD}$ instillation. $\mathrm{AD}$ - amiodarone. 
The results in group 4 (treated with U-74389G alone) were comparable to those in the control group (Table 1, Fig. 1-3).

The results obtained from our morphological study showed that $\mathrm{AD}$ led to moderate interstitial and peri vasal fibrosis, thickening of interstitial spaces and cellular infiltration, especially expressed on day 28.

\section{Discussion}

The experimental data of our study showed that the intratracheal instillation of $6.25 \mathrm{mg} / \mathrm{kg}$ iodine-containing amiodarone on days 0 and 2 caused toxic lung injury. The study results gave us reason to assume that amiodarone may affect antioxidant defense system in the lungs. The investigations on the lung homogenate showed that the activity of the key antioxidant enzyme, SOD, decreased significantly on day 3 , following treatment with amiodarone (group 2). At the same time, SOD activity after combined treatment with amiodarone and U-74369G (group 3) decreased less than in $\mathrm{AD}$ group.

The changes in CAT activity showed different kinetics. CAT levels in groups 2 and 3 increased significantly on day 3 , as compared with the controls. This index in group 3 remained below the enzyme activity measured in AD group, but no significant difference between both treated groups (2 and 3) was found.

The activity of another key antioxidant enzyme glutathione-peroxidase decreased significantly in both groups 2 and 3 on days 3 and 7, as compared with the controls.

It should be noted that in this study U-74389G mitigated the toxic effects of amiodarone regarding to key antioxidant enzyme activities.

An elevation in plasma hydroperoxide concentrations and MDA content on day 7 in the group treated with amiodarone was found, indicating a possible increase in lipid peroxidation and oxidant-induced damage in the lungs at this time point.

The literature shows contradictory data about the influence of amiodarone on the lipid peroxidation. Some authors accepted that oxidative stress plays a key role in AD-induced pneumotoxicity ${ }^{7,21}$ and that it causes membrane destabilization ${ }^{22}$. Examining the protective action of L-carnitine in the amiodarone-induced pulmonary changes, Gado and Aldahmash established that AD increased the levels of glutathione reductase and decreased the levels of SOD, catalase and MDA content in lung homogenate ${ }^{23}$. Amiodarone elevated the enzyme activities of SOD, catalase, as well as lipid peroxidation in other rat organs (liver, kidney, testicles) after oral administration ${ }^{24}$. Intratracheal instillation of amiodarone to hamsters induced an increase in lipid peroxidation in bronchoalveolar lavage fluid and lung homogenate ${ }^{25}$. Ribeiro et al demonstrated that amiodarone did not affect the antioxidant enzyme activities and inhibited about $70 \%$ of lipid peroxida$\operatorname{tion}^{26}$. Conversely, other researchers found a free radical production in $\mathrm{AD}$ solutions, and aryl radical formation in photolysis of anaerobic aqueous solutions of $\mathrm{AD}$, or $\mathrm{N}$-desethylamiodarone $\mathrm{e}^{27}$. It has been also suggested that the generation of hydroxyl radicals in concentrated $\mathrm{AD}$ aqueous solution was associated with the presence of $\mathrm{C}$-centered radical in AD molecule. Nicolescu et al proposed that mitochondrial dysfunction in peripheral lung epithelial cells in early phase, was more relevant cause inducing $\mathrm{AD}$ toxicity, than ROS overproduction ${ }^{27}$.

Alveolar macrophages have been shown to be the first cell type affected in the lung, resulting in a foamy transformation, a possible contributing process to initiation of phospholipidosis ${ }^{6,9}$. Foamy alveolar macrophages were recognized to be liable to change lung repair and/or progression of fibrosis after $\mathrm{AD}$ treatment. In our previous study, we found a significant increase in the number of macrophages in amiodarone-treated group ${ }^{28}$. The cytoplasm in these macrophages was foamy and vacuolated. Our results were in line with Nacca et $\mathrm{al}^{3}$, who mentioned that the classic finding was the lipid-laden macrophages in alveolar spaces, known as foam cells, in amiodarone-induced pulmonary toxicity. This drug also promoted the accumulation of phospholipids in tissues and had a potent inhibitory effect on lysosomal phospholipase, leading to accumulation of phospholipids in membrane-rich structures ${ }^{7,9}$. Amiodarone influenced the production of toxic oxygen radicals and may induce the accumulation of phospholipids in the tissues, with a direct cytotoxic effect on the alveolar-capillary membrane in the lung.

Although inflammation is not a prominent process, an inflammatory response is an important feature in AD-induced pulmonary toxicity. Inflammation involved the recruitment of specific cells, including polymorphonuclear neutrophils, lymphocytes, plasma cells and eosinophils. Inflammatory cells can induce tissue damage through the release of toxic substances, such as oxygen free radicals, proteases, and inflammatory mediators, such as cytokines and chemokines. In a previous article, we demonstrated an early AD inflammatory response in the lungs, by a fourfold increase of total cell number and protein content in BALF on day 3 after $\mathrm{AD}$ treatment, as well as a significant increase in neutrophil number, which remained elevated till day $28^{28}$. 
Amiodarone-induced pulmonary fibrosis is a serious complication, but its mechanism remains incompletely understood. By using electron microscopic and histological examinations, Mahdy demonstrated an expressed pulmonary fibrosis after chronic oral $\mathrm{AD}$ treatment in rats ${ }^{29}$. Repeated microinjuries associated with inflammatory process were considered catalysts of progression of the fibrotic response. An elevation in hydroxyproline content on days 14 and 28 after treatment with amiodarone supported the statement that AD may produce pulmonary fibrosis.

The 21-aminosteroid U74389G attenuated the effects of amiodarone on lipid peroxidation. The lazaroids inhibit membrane lipid peroxidation by scavenging peroxyl radicals, a mechanism similar to that of vitamin E. They potentiated vitamin E's antioxidant efficacy by slowing the oxidation of vitamin $E$ during linoleic acid peroxidation ${ }^{13}$. The lazaroids inhibited oxidant-mediated injury in isolated rat lungs after ischemia/reperfusion ${ }^{30}$. They also have a high affinity for the membrane lipids and by incorporation into the lipid bilayer because of their lipophilicity, the lazaroids produce cell membrane-stabilizing effects. The protonated piperazine nitrogen interacts with negatively charged phosphate-containing head groups of the membrane lipid bilayer. This action limits the movement of lipid peroxyl radicals within the membrane, thus reducing their interaction with fatty acids and inhibits lipid peroxidation. The investigations of Saija et al evidenced the strong antioxidant activity of U-74389G in a membranous system ${ }^{31}$. These authors speculated that $\mathrm{U}-74389 \mathrm{G}$ can act as scavenger of chain-propagating lipid peroxyl radicals within the membranes. The lazaroid prevents not only cell membranes against peroxidative stress, but also intracellular components.

The results obtained from our study showed that the development of pulmonary fibrosis was significantly inhibited by U-74389G on days 14 and 28 after amiodarone instillation on the basis of reduced hydroxyproline content and morphological examination.

\section{Conclusions}

In conclusion, the intratracheal amiodarone administration produced severe toxic damages of lung parenchyma in rats, assessed by biochemical markers in lung homogenate and plasma. Amiodarone affected antioxidant defense system in the lungs, promoted lipid peroxidation, and caused pulmonary fibrosis. The 21-aminosteroid U-74389G significantly inhibited lipid peroxidation and mitigated fibrous changes in rat lungs provoked by amiodarone.

\section{Acknowledgments}

This study was supported by a grant from the Medical University of Pleven, Bulgaria

\section{Compliance with Ethics Requirements:}

„The authors declare no conflict of interest regarding this article"

„The authors declare that all the procedures and experiments of this study respect the ethical standards in the Helsinki Declaration of 1975, as revised in 2008(5), as well as the national law"

„All institutional and national guidelines for the care and use of laboratory animals were followed"

\section{References}

1. Flieder D, Travis W. Pathologic characteristics of drug-induced lung disease. Clinics in Chest Medicine 2004;25(1):37-45.

2. Brien JF, Jimmo S, Brennan FJ, Ford SE, Armstrong PW. Distribution of amiodarone and its metabolite, $\mathrm{N}$-desethylamiodarone, in human tissues. Canadian Journal of Physiology and Pharmacology. 1987;65(3): 360-364.

3. Nacca N, Bhamidipati CM, Yuhico LS, Pinnamaneni S, Szombathy T. Severe amiodarone induced pulmonary toxicity. Journal of Thoracic Disease. 2012;4(6): 667-670.

4. Siddoway L. Amiodarone: Guidelines for use and monitoring. American Family Physician. 2003;68(11): 2189-2196.

5. Wilson BD, Lippmann ML. Pulmonary accumulation of amiodarone and $\mathrm{N}$-desethylamiodarone. Relationship to the development of pulmonary toxicity. The American Review of Respiratory Disease. 1990;141(6): 1553-1558.

6. Reasor MJ, Kacew S. An evaluation of possible mechanisms underlying amiodarone-induced pulmonary toxicity. Proceedings of the Society for Experimental Biology and Medicine. 1996;212(4): 297-304.

7. Jessurum GA, Crijns HJG. Amiodarone pulmonary toxicity. British Medical Journal. 1997;314(7081): 619-620.

8. Halliwell WHY. Cationic amphiphilic drug-induced phospholipidosis. Toxicologic Pathology. 1997;25(1): 53-60.

9. Bargout R, Jankov A, Dincer E, et al. Amiodarone induces apoptosis of human and rat alveolar epithelial cells in vitro. American Journal of Physiology. Lung Cellular and Molecular Physiology. 2000;278(5): L1039-1044.

10. Yasuda SU, Sausville EA, Hutchins JB, Kennedy T, Woosley RL. Amiodarone-induced lymphocyte toxicity and mitochondrial function. Journal of Cardiovascular Pharmacology. 1996;28(1): 94-100.

11. Bolt MW, Card JW, Racz WJ, Brien JF, Massey TE. Disruption of mitochondrial function and cellular ATP levels by amiodarone and $\mathrm{N}$-desethylamiodarone in inhalation of amiodarone-induced pulmonary cytotoxicity. Journal of Pharmacology and Experimental Therapeutics. 2001;298(3): 1280-1289.

12. Jacobsen EJ, McCall JM, Ayer DE, et al. Novel 21-aminosteroids that inhibit iron-dependent peroxidation and protect against nervous system trauma. Journal of Medicinal Chemistry. 1990;33(4): 1145-1151.

13. Braughler JM, Pregenzer JF, Chase RL, Duncan LA, Jacobsen EJ, McCall JM. Nowel 21-aminosteroids as potent 
inhibitors of iron-dependent lipid peroxidation. Journal of Biological Chemistry. 1987; 262(22):10438-10440.

14. Taylor MD, Antonini JM, Roberts JR, et al. Intratracheal amiodarone administration to F3444 rats directly damages lung airway and parenchymal cells. Toxicology and Applied Pharmacology 2003;188(2): 92-103.

15. Maral I, Puget K, Michelson H. Comparative study of SOD, catalase and GSH-Px levels in erythrocytes of different animals. Biochemical and Biophysical Research Communications 1977;77(4): 1532-1535.

16. Koroljuk MA, Ivanova LI, Maiorova IG, Tokarev VE. A method of determining catalase activity. Laboratornoe delo 1988;1: 16-19 [Russian].

17. Bergmeyer HU, Gawehn K, Grass M. Enzymes as biochemical reagents, in: Methods of Enzymatic Analysis, HU Bergmeyer (ed). New York, Academic Press, 1974, 425-522.

18. Ohkawa H, Ohishi N, Yagi K. Assay for lipid peroxides in animal tissues by thiobarbituric acid reaction. Analytical Biochemistry. 1979;95(2): 351-358.

19. Bergman I, Loxley R. Two improved and simplified methods for the spectrophotometric determination of hydroxyproline. Analytical Chemistry. 1963;35(12): 1961-1965.

20. Yagi K. Lipid peroxides in human diseases. Chemistry and Physics of Lipids. 1987;45(2-4): 337-351.

21. Leeder RG, Brien JF, Massey TE. Investigation of the role of oxidative stress in amiodarone-induced pulmonary toxicity in the hamster. Canadian Journal of Physiology and Pharmacology. 1994;72(6): 613-621.

22. Golli-Bennour EE, Bouslimi A, Zouaoui O, Nouira S, Achour A, Bacha H. Cytotoxicity effects of amiodarone on cultured cells. Experimental and Toxicologic Pathology 2012;64(5): 425-430.
23. Gado AM, Aldahmash BA. Protective effect of L-carnitine against amiodarone-induced lung toxicity in rats. Internet Journal of Toxicology 2013;10(1): 1-9.

24. Chakraborty A, Mondal C, Sinha S, Mandal J, Chandra AK. Amiodarone induced oxidative stress in stress-vulnerable organs of adult male rats. Asian Journal of Pharmaceutical and Clinical Research 2014;7(4): 177-183.

25. Blake TL, Reasor MJ. Acute pulmonary inflammation in hamsters following intratracheal administration of amiodarone. Inflammation 1995;19(1): 55-65.

26. Ribeiro SM, Campello AP, Nascimento AJ, Kluppel ML. Effect of amiodarone (AMD) on the antioxidant enzymes, lipid peroxidation and mitochondrial metabolism. Cell Biochemistry and Function 1997;15(3): 145-152.

27. Nicolescu AC, Comeau JL, Hill BC, et al. Aryl radical involvement in amiodarone-induced pulmonary toxicity: Investigation of protection by spin-trapping nitrones. Toxicology and Applied Pharmacology 2007;220(1): 60-71.

28. Stavreva GT, Shopova VL, Dancheva VY, Stoyanova A, Terziev L. Effect of 21-aminosteroid U-74389G on markers for pneumotoxicity in rat bronchoalveolar lavage after intratracheal amiodarone administration. Journal of Biomedical and Clinical Research 2008;1(1): 30-39.

29. Mahdy AA. The possible ameliorative effect of selenium and vitamins combination against amiodarone-induced alveolar damage in albino rat: Histological and immunohistochemical study. Journal of American Science 2014;10(4s): 61-71.

30. Haynes J, Seibert A, Bass JB, Taylor AE. U-74389A inhibition of oxidant mediated lung injury. American Journal of Physiology. 1970;259(1 Pt 2): H144-148.

31. Saija A, Tomaino A, Pellegrino ML, Giuffrida N, Trombetta $\mathrm{D}$, Castelli F. In vitro evaluation of the antioxidant activity and bio membrane interaction of the lazaroid U-74389G. Life Sciences 2001;68(12): 1351-1366. 